\title{
Diagnóstico das áreas de preservação permanente das microbacias hidrográficas do município de Bandeirantes - Paraná
}

\section{Diagnosis of the permanent preservation areas in the watersheds of municipal district of Bandeirantes, Paraná, Brazil}

\author{
Luiz Carlos Reis ${ }^{1 *}$; Teresinha Esteves da Silveira Reis²; Otávio Jorge Grigoli Abi Saab ${ }^{3}$
}

\section{Resumo}

\begin{abstract}
A expansão das fronteiras agrícolas, o desenvolvimento industrial e o aumento dos índices populacionais demandaram aumentos substanciais na produção de alimentos. Estes fatores levaram à degradação crescente dos recursos naturais. A devastação das áreas de florestas ao longo dos rios e córregos, entorno das nascentes e topos de morros, no passado, obrigam sua recomposição, por força de lei, como áreas de preservação permanente (APP). Este trabalho teve por objetivo delimitar as microbacias do município de Bandeirantes, mensurar as áreas de preservação permanente, total e existentes, ao longo dos cursos d'água, nascentes e topo de morros e identificar o uso conflitivo destas áreas. Utilizou-se o sistema de informação geográfica SPRING 4.1, imagem do Landsat ETM+, bandas 2, 3, 4 e 5, base cartográfica do IBGE, escala 1:50000 e fotografias aéreas, escala 1:25000. Verificou-se que o município apresenta $8,6 \%$ das APPs com mata ciliar, sendo $11,38 \%, 8,21 \%$ e 5,25\% referentes a rios, córregos e nascentes, respectivamente. As APPS referentes a topo de morros e declividades superiores a $100 \%$ têm área equivalente a 24,94 ha e 8,7 ha, no entanto $100 \%$ destas áreas encontram-se sem mata. As microbacias que apresentaram menor índice de APP foram aquelas com melhor aptidão agrícola.
\end{abstract}

Palavras-chave: Mata ciliar, uso agrícola, sistema de informação geográfica (SIG)

\begin{abstract}
The expansion of the agricultural limits, the industrial development and the increase of populations indexes demanded substantial increases in the production of victuals. These factors took to the growing degradation of the natural resources. The devastation of the areas of forests along the rivers and streams, around the riverhead and tops of hills, in the past, they force its recomposition, for law force, as permanent preservation areas (PPA's). This work had for objective to define the watersheds of the municipal district of Bandeirantes - PR, Brazil, to measure the permanent preservation areas, total and existent, along the courses of water, riverhead and top of hills and to identify the conflict use of the soil in these areas. The geographical information system was used SPRING 4.1, image of Landsat ETM+, bands 2, 3, 4 and 5, cartographic base of the IBGE, scale 1:50000 and aerial pictures, scale 1:25000. It was verified that the municipal district presents $8,6 \%$ of PPA's with ciliary forest, being $11,38 \%$, referring $8,21 \%$ and $5,25 \%$ to rivers, streams and riverhead, respectively. Referring PPA's meets of top of hills and in superiors slopes at $100 \%$, they have equivalent area for 24,94 ha and 8,7 ha, however $100 \%$ of these areas are without forest. The watersheds that presented smaller index of PPA's was those with better agricultural aptitude.
\end{abstract}

Key words: Agricultural use, remote sensing, geographic information system (GIS)

\footnotetext{
1 Professor do Departamento de Engenharia e Desenvolvimento Agrário, Faculdades Luiz Meneghel, Universidade Estadual do Norte do Paraná, Bandeirantes- PR. Doutorando pelo Programa de Pós-Graduação em Agronomia da Universidade Estadual de Londrina (UEL). E-mail: 1creis2006@uol.com.br

2 Professora, Doutora, Departamento de Engenharia e Desenvolvimento Agrário, Faculdades Luiz Meneghel, Universidade Estadual do Norte do Paraná, Bandeirantes - PR.

3 Professor, Doutor, Departamento de Agronomia, Universidade Estadual de Londrina (UEL), Londrina - PR.

* Autor para correspondência.
} 


\section{Introdução}

O rápido aumento da população mundial, aliado ao desenvolvimento industrial e agrícola, levou à séria degradação do ambiente global e à demanda crescente por alimentos na mesma proporção. É necessário, para que a ocupação do espaço territorial e a produção agrícola sejam equacionadas, estabelecer e implementar uma política agrícola que contemple além da produção de alimentos, a preservação do meio ambiente, especialmente o solo e os recursos hídricos e a adoção de técnicas de avaliação e de diagnóstico que acompanhem a dinâmica espaço temporal do uso da terra (SANO; ASSAD; ORIOLI, 1998).

No Estado do Paraná a cobertura com florestas nativas, em 1890, era da ordem de $83,4 \%$ de sua superfície(FUNDAÇÃOSOS MATAATLÂNTICA, 2003), cuja ocupação resultou numa perda considerável das florestas, restando fragmentos isolados. Segundo Rodrigues (1998) apud Primack e Rodrigues (2001), na região norte do estado, resta apenas 7,5\% de sua área em fragmentos florestais. $\mathrm{O}$ processo de ocupação de suas terras fundamentouse principalmente, em fatores econômicos, sociais e culturais, em detrimento de sua aptidão agrícola (INSTITUTO AGRONÔMICO DO PARANÁIAPAR, 1999).

A legislação ambiental brasileira pode ser considerada ampla, entretanto, a deficiência em meios e materiais, dentre outros fatores, para apurar com rigor as agressões ao meio ambiente, tem dificultado sua aplicação (CRESTANA; TOLEDO FILHO; CAMPOS, 1993).

O geoprocessamento apresenta-se como alternativa viável para reduzir, significativamente, as deficiências relativas à aplicação da legislação, no instante em que viabiliza a integração de informações cartográficas e tabulares. Esta integração permite o estabelecimento de relações de causa e efeito, através da análise ambiental, além dos aspectos temporais, impraticáveis via tradicionais métodos (TOWSHEND, 1992; XAVIER DA SILVA, 1992), e auxilia substancialmente na investigação da adequação do uso da terra em áreas de preservação permanente (AULICINO et al., 2000).

Delimitar as áreas de preservação permanente em topos de morro, pelos métodos tradicionais da topografia, é um desafio, em razão dos aspectos técnicos e econômicos, principalmente, em grandes áreas, devido aos custos e complexidade das operações de campo (PESSOA et al., 1997). Entretanto, a incorporação de alguns algoritmos aos SIGs tem tornado possível processar, de forma rápida e eficiente, os dados necessários para caracterização das variáveis morfométricas do terreno (OLIVEIRA, 2002).

A tecnologia de sensoriamento remoto, ao nível orbital, aliada às técnicas de geoprocessamento permite vários tipos de tratamento de dados da superfície terrestre e a obtenção de resultados em diferentes escalas. Os sistemas de informações geográficas podem ser considerados como uma ferramenta muito importante na identificação e avaliação de áreas ocupadas por propriedades de diferentes portes e pela vegetação natural, além do monitoramento anual do desflorestamento em certas regiões (ASSAD, 1998; SHIMABUKURO et al. 1998; LOCH; KIRCHINER, 2000; REIS; BARROS; REIS, 2004).

Segundo Magalhães e Ferreira (2000), um dos grandes desafios para a conservação ambiental é a preservação e recuperação de áreas naturais consideradas estratégicas, dentre elas, destacamse as áreas de preservação permanente (APPs), dentro de uma microbacia, pois são responsáveis pela manutenção, preservação e conservação dos ecossistemas existentes, principalmente os aquáticos. A vegetação ripícola tem como papel principal, a proteção das margens de rios, lagos, córregos e nascentes, servindo como filtro e amortecimento dos impactos provenientes das áreas que os circundam. A barreira física imposta por elas funciona como um dreno para deposição do material trazido pelas enxurradas, diminuindo a quantidade de material 
em suspensão, que levam elementos indesejáveis para as águas (PRIMACK; RODRIGUES, 2001).

No município de Bandeirantes-PR, a substituição do café por outras culturas e pastagens, a expansão de suas fronteiras e o modelo fundiário adotado na colonização da região, com lotes alongados, dos espigões aos cursos d'água, provocaram drástica diminuição das áreas de florestas, inclusive aquelas localizadas em áreas de preservação permanente (APP) como os rios Cinzas, utilizado como manancial de abastecimento e Laranjinha, seu principal afluente, que são divisas naturais do município.

Este trabalho teve por objetivo mensurar, em cada uma das microbacias do município de Bandeirantes - PR, as áreas de preservação permanente existentes ao longo dos cursos d'água, entorno das nascentes e topo de morros e avaliar o uso conflitivo naquelas a recompor, através de um Sistema de Informações Geográficas e técnicas de sensoriamento remoto.

\section{Material e métodos}

O trabalho foi desenvolvido no município de Bandeirantes, Estado do Paraná, localizado no retângulo compreendido pelas coordenadas $50^{\circ}$ 29' 44" a 50 09' 43" W e $23^{\circ} 17^{\prime}$ ' 5" a $23^{\circ} 00^{\prime} 59^{\prime}$ " S. O clima, Cfa pela classificação de Köeppen, é subtropical úmido, mesotérmico com verão quente, estiagem no inverno, precipitações médias anuais de $1.300 \mathrm{~mm}$, média de $30 \mathrm{~mm}$ no mês mais seco e geadas menos freqüentes.

Utilizou-se um Sistema de Informações Geográficas (SIG), denominado Sistema de Processamento de Informações Georreferenciadas (SPRING), versão4.1, desenvolvidoedisponibilizado pelo Instituto Nacional dePesquisas Espaciais(INPE, 1999). A base cartográfica, constituída pelas cartas elaboradas pelo IBGE, escala 1:50.000, projeção UTM, datum vertical: Imbituba (SC) e Horizontal SAD 69, folhas MI 2760-1, MI 2760-2, MI 2760-3 e MI 2760-4, foi inserida no sistema via "scanner" de mesa e, em seguida procedeu-se à digitalização das curvas de nível com eqüidistância vertical de 20 $\mathrm{m}$, gerando um modelo numérico de terreno (MNT) e da rede de drenagem, em um plano de informação temático. Conforme INPE (1999), digitalização é um processo que permite converter dados espaciais do meio analógico para o digital. Posteriormente, gerou-se uma grade triangular cujos valores de altitudes possibilitaram a determinação dos divisores de águas das microbacias hidrográficas.

Os fragmentos florestais, bem como o uso do solo, foram obtidos a partir do processamento da imagem do Landsat 7 ETM+,WRS 221_76 de 15/04/2001 bandas 2, 3, 4 e 5. Dentre as técnicas de realce da imagem, utilizou-se a manipulação de contraste e operações entre bandas. A operação utilizada foi a divisão entre bandas que consiste numa operação não linear, com a finalidade de realçar as diferenças espectrais de um par de bandas, caracterizando determinadas feições da curva de assinatura espectral de alguns alvos. Para aumentar o contraste entre solo e vegetação, utilizou-se as bandas referentes ao vermelho e infravermelho próximo, constituindo assim, o chamado índice de vegetação normalizada (NDVI). Desta forma há maior possibilidade de detecção dos alvos, uma vez que, realça as diferenças espectrais entre as bandas $3(0,63-0,69 \mu \mathrm{m})$ e 4 $(0,76-0,90 \mu \mathrm{m})$, diminui o efeito de sombreamento causado pelo fator topográfico e realça solo e vegetação conforme manual do SPRING (INPE, 2005). A classificação da imagem, para a obtenção dos fragmentos florestais e uso do solo, foi realizada através do método de classificação supervisionado, classificador battacharia. Em seguida tais polígonos foram ajustados, poligonalizados e armazenados em um plano de informação (PI) temático.

Considerando a resolução da imagem, a largura dos córregos e as nascentes, optou-se por realçar o teor de umidade do solo e plantas para melhor contornar os cursos d'água. Para isso, utilizou-se as bandas $5(1,55-1,75 \mu \mathrm{m})$ e $7(2,08-2,35 \mu \mathrm{m})$ e os componentes principais gerados. A importância da banda 5 está na análise de umidade de vegetação 
e a banda 7, por ser uma banda geológica, permite realçar as condições de solo. Segundo Instituto Nacional de Pesquisas Espaciais (2005) componentes principais é uma técnica de realce que reduz ou remove a redundância espectral, ou seja, gera um novo conjunto de imagens cujas bandas individuais apresentam informações não disponíveis em outras bandas. Esta transformação é derivada da matriz de covariância entre as bandas e gera um novo conjunto de imagens onde cada valor de "pixel" é uma combinação linear dos valores originais. O número de componentes principais é igual ao número de bandas espectrais utilizadas e são ordenadas de acordo com o decréscimo da variância de nível de cinza. A primeira componente principal tem a maior variância (maior contraste) e a última, a menor variância. Os dados estatísticos deste processamento constam da tabela 1 .

Tabela 1. Dados estatísticos do processamento por componentes principais das bandas 5 e 7 .

\begin{tabular}{ccccc}
\hline PI & Média & Variância & C Componente & \% Informação \\
\hline Banda 5 & 74,94 & 419,31 & $\mathrm{P} 1$ & 94,65 \\
Banda 7 & 45,85 & 274,69 & $\mathrm{P} 2$ & 5,35 \\
\hline
\end{tabular}

Através da matriz de autovalores, constatou-se que a banda 5 contribui um pouco mais do que a banda 7 , na componente principal e que $94,65 \%$ das informações contidas em ambas as bandas estão na componente principal P1, que pode ser caracterizada pela equação:

$$
\mathrm{P} 1=\mathrm{B} 5 * 0,79+\mathrm{B} 7 * 0,62 .
$$

Após este processamento, o PI referente à hidrografia extraída da base cartográfica do IBGE, foi ajustada manualmente através da edição topológica, modo passo, com fator de digitalização de $0,15 \mathrm{~mm}$, considerando as bandas com as respectivas médias de contraste: 3R $(50,11)$, 4G $(92,39)$ e P1B $(129,4)$. As áreas de preservação permanente (APPs) referentes a rios, córregos e nascentes, foram obtidas a partir da ferramenta disponível no sistema denominada "mapa de distância", conforme legislação vigente. As APPs existentes foram obtidas a partir do cruzamento entre os planos de informação das APPs e dos fragmentos florestais, obtidos na classificação da imagem.
Obteve-se as APPs referentes a topo de morro e áreas com declividade maior que $100 \%$, considerando a base altimétrica inserida no modelo numérico do terreno, cujas classes de declividade foram obtidas a partir de uma grade triangular. Para a extração de topo de morro, fez-se necessário identificar as áreas com declividade maior que 30\% e aquelas, cuja diferença de nível entre a base e o topo era $\geq 50 \mathrm{~m}$. Nesse processo de identificação de morros, para atender aos dispositivos da resolução $\mathrm{n}^{\mathrm{o}}$ 303, do Conselho Nacional do Meio Ambiente - CONAMA, de 20/03/2002, foram gerados perfis das linhas de maior declive nas elevações, utilizando a ferramenta perfil, do SPRING. Após identificação, o terço superior foi delimitado e as áreas contabilizadas.

Para melhor análise das condições de uso conflitivo das APPs, inseriu-se no sistema o mapa da aptidão das terras do município, obtido por Reis (2003). As informações obtidas no sistema foram validadas "in loco" por amostragem e através da análise dos pares de fotografias aéreas pancromáticas, escala 1:25000, utilizando um estereoscópio de espelho modelo Zeiss. 


\section{Resultados e discussão}

O Código Florestal Brasileiro, Lei $\mathrm{n}^{\circ} 4.771 / 65$ (BRASIL, 1965), em seu artigo $2^{\circ}$, estabelece as faixas marginais ao longo dos rios e córregos, conforme sua largura. A resolução do CONAMA n ${ }^{\circ}$ 303, de 20/03/2002, que dispõe sobre parâmetros, definições e limites das Áreas de Preservação
Permanente, em seu artigo $2^{\circ}$, enfatiza curso d'água e nascentes perenes ou intermitentes. Considerando esses aspectos, constatou-se, em todo o município, a existência de 561 nascentes e 65 córregos que deságuam nos rios principais, distribuídos nas 16 microbacias que foram delimitadas, sendo oito voltadas para o Rio Cinzas e oito para o Rio Laranjinha, conforme Tabela 2.

Tabela 2. Quantidade de rios, córregos e nascentes com as respectivas áreas de mata ciliar existente e total das microbacias do município de Bandeirantes - PR.

\begin{tabular}{|c|c|c|c|c|c|c|c|c|c|}
\hline \multirow{2}{*}{\multicolumn{2}{|c|}{ Microbacia }} & \multirow{2}{*}{$\begin{array}{c}\mathrm{N}^{0} \\
\text { nasc. }\end{array}$} & \multirow{2}{*}{$\begin{array}{c}\mathbf{N}^{o} \\
\text { cor. }^{1}\end{array}$} & \multicolumn{3}{|c|}{ Mata ciliar total (ha) } & \multicolumn{3}{|c|}{ Mata ciliar existente (ha) } \\
\hline & & & & nasc. & rios & cor. & nasc & rios & cor. \\
\hline \multirow{8}{*}{ 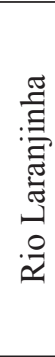 } & Iara & 5 & 4 & 3,9 & 67,5 & 52,7 & 0,0 & 1,2 & 0,0 \\
\hline & Limeira & 9 & 6 & 7,1 & 166,5 & 76,9 & 0,0 & 4,7 & 1,1 \\
\hline & A. Branca & 15 & 2 & 11,8 & 26,9 & 165,4 & 0,0 & 1,4 & 0,1 \\
\hline & A. Divisa & 19 & 3 & 14,9 & 44,9 & 104,3 & 0,0 & 9,8 & 1,9 \\
\hline & A. Vermelha & 15 & 2 & 11,8 & 60,1 & 107,6 & 0,0 & 8,6 & 10,0 \\
\hline & Fartura & 36 & 3 & 28,3 & 40,9 & 215,4 & 0,1 & 0,0 & 9,4 \\
\hline & Cabiúna & 56 & 1 & 44,0 & 27,6 & 400,6 & 7,3 & 8,4 & 58,1 \\
\hline & R. Índios & 29 & 2 & 22,8 & 6,6 & 236,7 & 3,4 & 0,0 & 52,4 \\
\hline \multirow{8}{*}{ 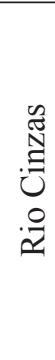 } & Jacutinga & 8 & 6 & 6,3 & 107,9 & 112,8 & 0,0 & 12,8 & $\overline{6,6}$ \\
\hline & A. Antas ${ }^{2}$ & 83 & 2 & 65,2 & 61,7 & 656,2 & 3,0 & 2,50 & 38,5 \\
\hline & A. Caixão & 26 & 1 & 20,4 & 47,7 & 263,6 & 0,0 & 4,1 & 34,2 \\
\hline & Paraguai & 41 & 8 & 32,2 & 209,4 & 351,0 & 1,2 & 32,8 & 23,2 \\
\hline & A. Onça & 26 & 6 & 20,4 & 135,4 & 181,4 & 1,4 & 35,1 & 3,4 \\
\hline & S. Paulo & 42 & 7 & 33,0 & 145,5 & 304,5 & 0,7 & 5,2 & 4,4 \\
\hline & Cateto & 87 & 10 & 68,3 & 105,9 & 544,5 & 3,0 & 13,6 & 52,3 \\
\hline & Perobas & 64 & 2 & 50,2 & 96,0 & 492,4 & 3,1 & 13,6 & 54,4 \\
\hline \multicolumn{2}{|c|}{ Total } & 561 & 65 & 440,6 & 1350,5 & 4265,8 & 23,1 & 153,7 & 349,8 \\
\hline
\end{tabular}

${ }^{1} \mathrm{n}^{\mathrm{o}}$ de córregos que deságuam nos rios Cinzas e Laranjinha;

2 inclui o perímetro urbano.

Verificou-se que, para atender a legislação vigente, a área total de mata ciliar deve ser de 6056,9 ha, entretanto, as áreas existentes somam apenas 526,68 ha, equivalentes a $8,7 \%$ do total.

Observou-se total ausência de matas ciliares ao redor de nascentes nas microbacias Água Yara, Limeira, Água Branca, Água da Divisa, Água Vermelha, Água da Fartura, Jacutinga e Água do Caixão; ao longo dos córregos, nas microbacias
Iara e Água Branca e, ao longo dos rios, nas microbacias Água da Fartura e Ribeirão dos Índios. Das APPs referentes a rios, córregos e nascentes, apenas $11,38 \%, 8,21 \%$ e 5,25\% respectivamente, apresentaram vegetação ripária.

A figura 1 caracteriza as áreas de preservação permanente, conforme código florestal, nas microbacias hidrográficas e os remanescentes florestais, obtidos por Reis (2003). 


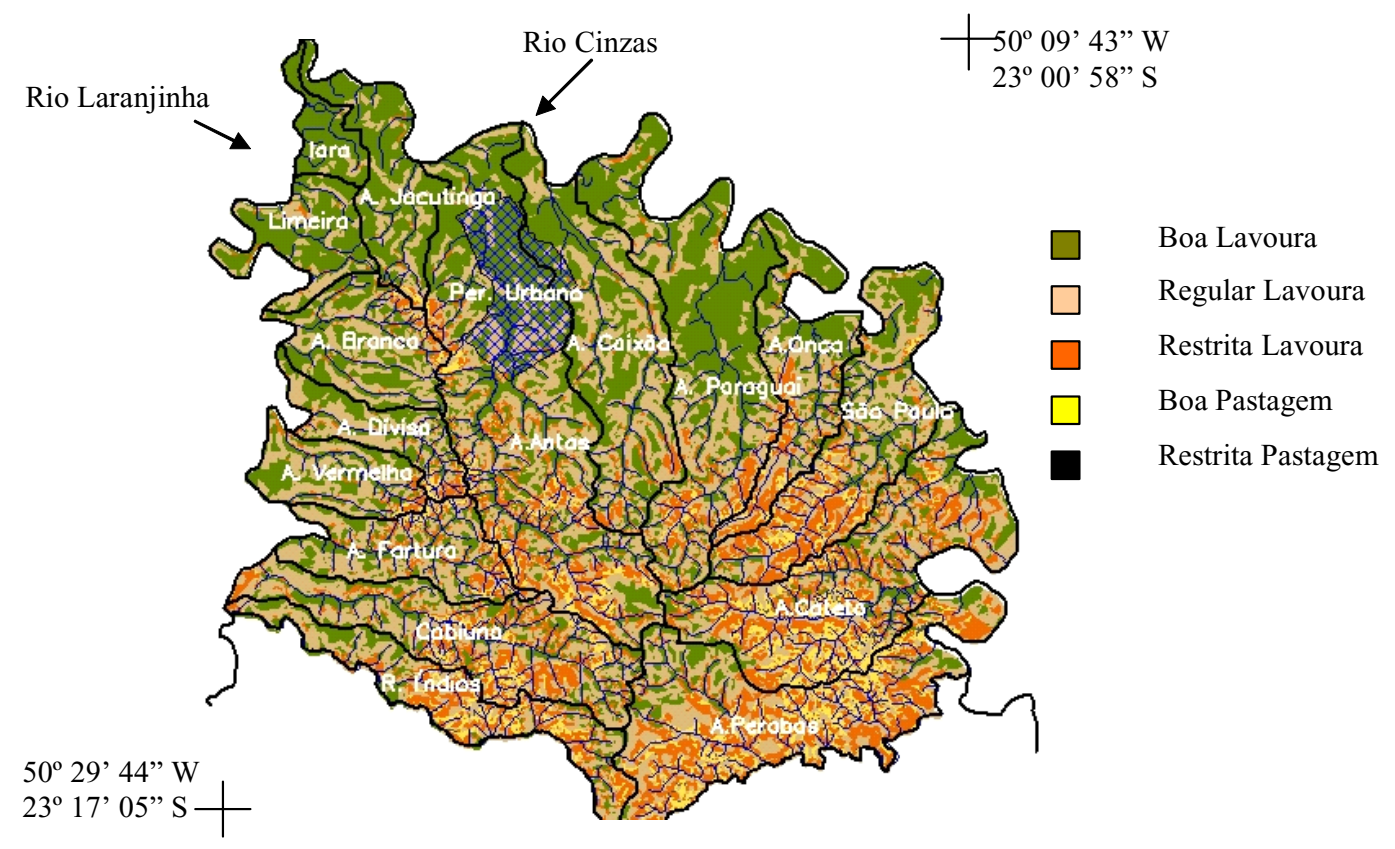

Figura 1. Mapa das microbacias hidrográficas com respectivas áreas de preservação permanentes referentes aos mananciais.

Para APPS de topo de morro e em declividades superiores a $100 \%$ verificou-se área equivalente a 24,94 ha e 8,7 ha respectivamente, sendo que o total destas áreas foram ocupados por pastagem. A identificação de topo de morro mostrou-se trabalhosa, pois na legislação ambiental é necessário atender a declividade e diferença de nível entre a base e o topo. As dificuldades para delimitar as áreas de APPs em topo de morro também foram apontadas por Hott, Guimarães e Miranda (2005), Nascimento et al. (2005) e Ribeiro et al. (2005).

Reis (2003), utilizando a metodologia preconizada por Ramalho Filho e Beek (1995), através de SIG, avaliou a aptidão agrícola das terras do município. A análise da distribuição das terras quanto à aptidão agrícola (Figuras 2 e 3 ) e da quantidade de mata ciliar (Tabela 2) possibilitou constatar que as microbacias com maior déficit de matas ciliares foram as que apresentaram terras de maior potencial agrícola, destacando as microbacias Iara, Jacutinga, Limeira, Paraguai, Água do Caixão e Água Branca. Já aquelas com maiores restrições de uso, tais como Perobas, Cateto, Cabiúna, S. Paulo e Água da Fartura apresentaram maiores índices de APP com mata.

O potencial de uso das terras foi preponderante para a ocupação irregular das APPs. O conflito de uso nas terras legalmente protegidas também foi verificado por Nascimento et al. (2005). 


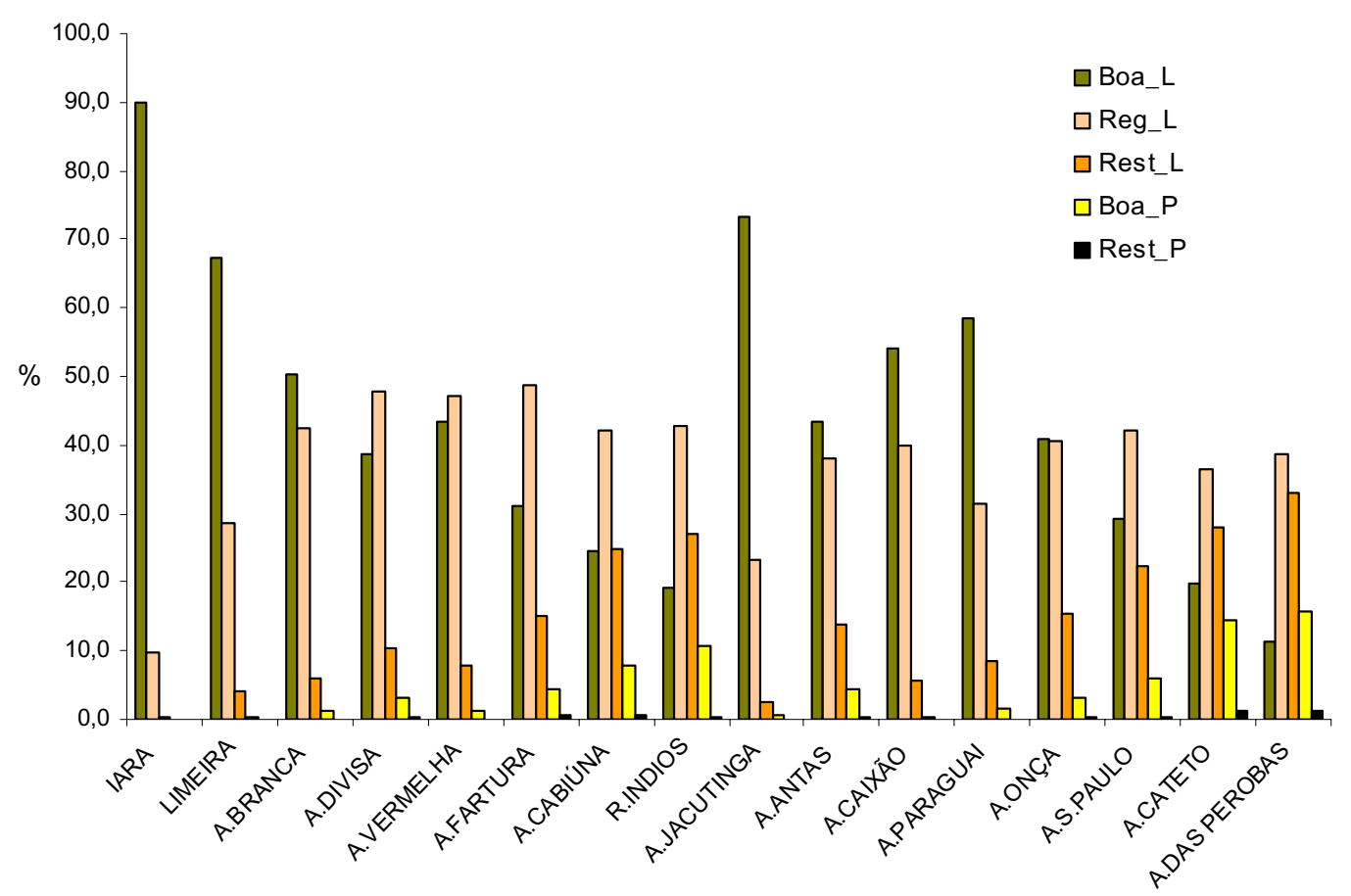

Figura 2. Microbacias hidrográficas, mapa de aptidão agrícola, nível de manejo B, e hidrografia do município de Bandeirantes-PR.

Fonte: REIS (2003)

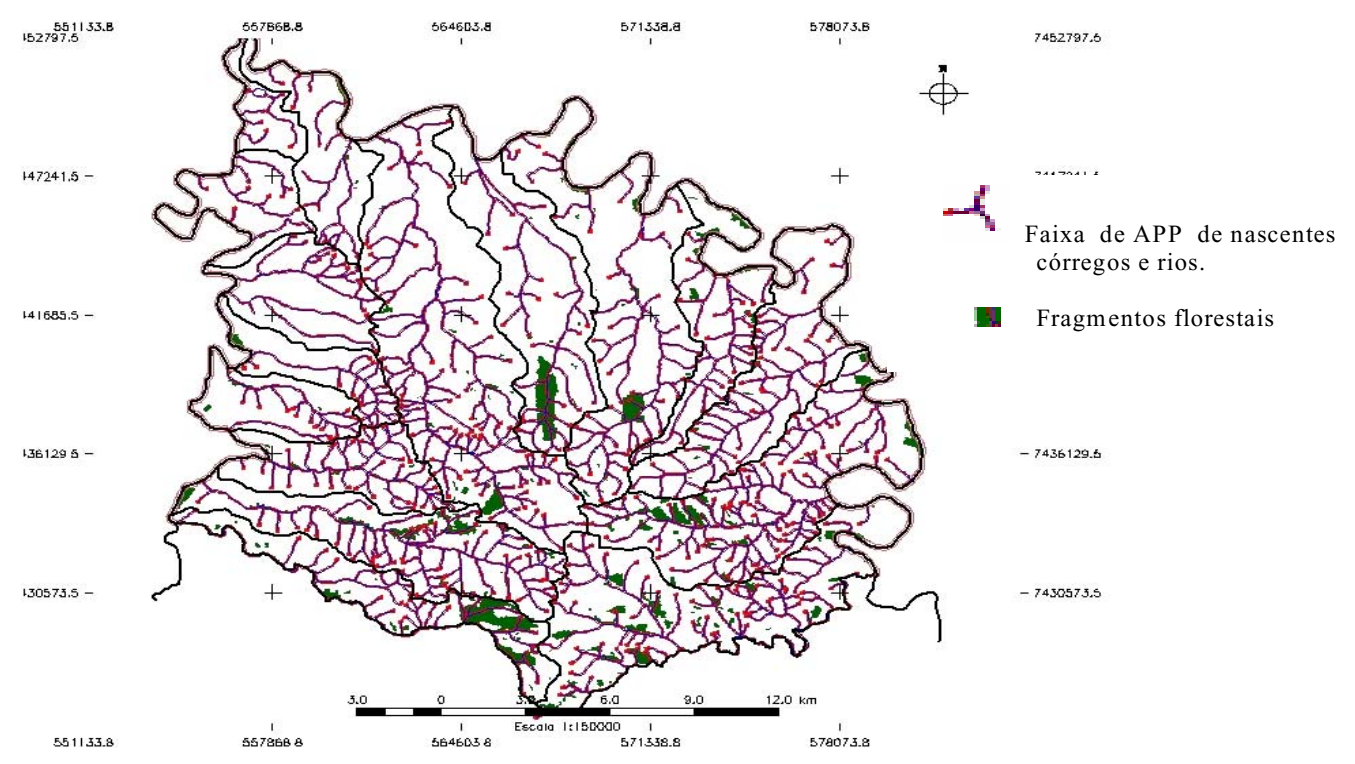

Figura 3. Distribuição das áreas conforme classes de aptidão agrícola (\%) nas microbacias hidrográficas do município de Bandeirantes $-\mathrm{PR}$.

Fonte: REIS (2003) 
Os usos do solo nas áreas de APPs são os mais variados, predominando a pastagem, cultura anual, cana de açúcar e outros, conforme demonstra a figura 4. A área de APP correspondente aos córregos totaliza aproximadamente 4.266 ha, e, no entanto, apenas 350 ha são ocupados por mata. A pastagem, cultura anual, como soja e milho, outros usos (neste tema estão incluídos culturas diversas, tais como: alfafa, mandioca, fruticultura, áreas em pousio, piscicultura), e cana ocupam respectivamente $32,5 \%, 18,0 \%, 15,6 \%$ e $12,1 \%$ das áreas destinadas a APPs. Do total de APP das nascentes, 440,6 ha, observou-se que apenas 5\% são vegetadas por mata, sendo que o uso preponderante destas áreas refere-se à pastagem seguida por culturas anuais na ordem 28\% e 22\% respectivamente. Quanto aos rios, o município possui grande parte de suas divisas delimitadas pelos rios Laranjinha e Cinzas. Considerando apenas o território municipal, o total de APP para ambos é de 1.350,5 ha. Neste estudo observou-se que outros usos, pastagem, cultura anual e cana, ocuparam respectivamente $37,8 \%$, $17,8 \% \%, 12,1 \%$ e $12 \%$ das APPs. Apenas 153,7 ha, ou seja, $11,4 \%$ são ocupados por mata, atendendo a legislação ambiental.

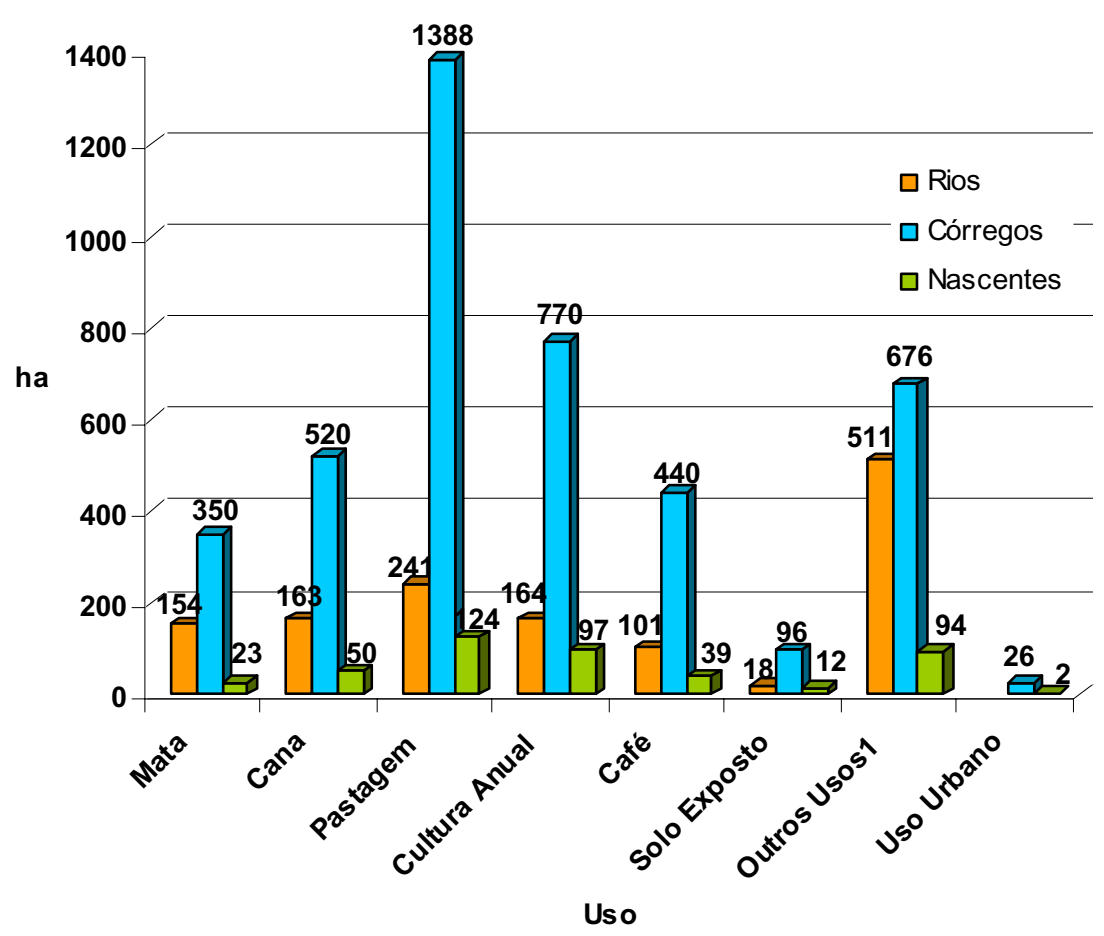

Figura 4. Usos das áreas de preservação permanente referentes a rios, córregos e nascentes do município de Bandeirantes - PR.

Valeri e Senô (2003) em um estudo para avaliar as condições das propriedades agrícolas na região de Jaboticabal (SP), constataram que apenas as propriedades onde havia diversidade de uso apresentavam APP preservada, e que a maioria das APPs não preservadas apresentava gramíneas invasoras, como o capim colonião (Panicum maximum) e advertem que podem impedir a regeneração natural das espécies arbóreas.

No perímetro urbano, constatou-se que apenas uma das nascentes apresenta-se com APP florestada e que os córregos têm parte canalizada e apenas 3,28 ha de mata ciliar. 
O código florestal estabelece que na área urbana prevaleça o que dispõe o plano diretor e a lei de uso do solo de cada município. A lei orgânica do município de Bandeirantes, de 19/04/1990, não faz menção a tais áreas.

O conceito de função ambiental das APPs, enfatizada pela legislação ambiental, baseia-se na preservação dos recursos hídricos, do solo, da paisagem, da biodiversidade, do fluxo gênico da flora e fauna e da estabilidade geológica. É de fundamental importância a recomposição destas áreas para garantir a sustentabilidade ambiental e assegurar o bem estar das populações.

\section{Conclusões}

1 - Do total de 6056,9 ha de áreas de preservação permanente referente à mata ciliar, o município apresenta apenas $8,7 \%$, sendo $11,38 \%$ nas margens dos rios, $8,21 \%$ nos córregos e $5,25 \%$ nas nascentes. A área de APP referente a topo de morro e em declividades superiores a $100 \%$ equivalem a 24,94 ha e 8,7 ha respectivamente e encontram-se totalmente desprovidas de mata.

2-Os usos conflitivos mais comuns das APPs são pastagem, cana-de-açúcar, culturas anuais e culturas diversas como alfafa, mandioca e fruticultura. As microbacias com menor índice de mata ciliar são aquelas com terras de melhor aptidão agrícola.

3 - No perímetro urbano, verificou-se que apenas uma das nascentes apresentava mata ciliar e nos córregos, 3,28 ha de mata ciliar. A lei orgânica do município não contempla tais questões, como determina a legislação ambiental.

\section{Referências}

ASSAD, M. L. L. Sistemas de informações geográficas na avaliação da aptidão agrícola de terras. In: ASSAD, E. D.; SANO, E. E. (Ed.). Sistema de informações geográficas: aplicações na agricultura. Planaltina: EMBRAPA/CPAC, 1998. p. 173-199.
AULICINO, L. C. M.; RUDORFF, B. F. T.; MOREIRA, M. A.; MEDEIROS, J. S.; SIMI JÚNIOR, R. Subsídios para o manejo sustentável da bacia hidrográfica do rio Una através do uso de técnicas de geoprocessamento e sensoriamento remoto. In: SIMPÓSIO LATINO AMERICANO DE PERCEPCIÓN REMOTA, 9., 2000, Puerto Iguazu. Anais... Lujan: SELPER, 2000. p. 899908.

BRASIL.Lein. 4.771, de 15 de setembro de 1965. Institui o novo Código Florestal. Disponível em: $<$ http://www.cna. org.br/site/desvio.php?ag=0\&origem=14511\&a=14526. Acesso em: 23 abr. 2006.

CRESTANA, M.S.M.; TOLEDO FILHO, D. V.; CAMPOS, J. B. Florestas: sistemas de recuperação com essências nativas. Campinas: CATI, 1993. 60p.

FUNDAÇÃO SOS MATA ATLÂNTICA. As comunidades tradicionais da Mata Atlântica: desafios da sustentabilidade da Mata Atlântica 1998 - 2003. Disponível em: $\quad<\mathrm{http}: / / \mathrm{www}$.sosmataatlantica.org. br/?secao $=$ conteudo\&id $=3 \_6 \_4>$. Acesso em: 23 abril 2006.

HOTT, M. C.; GUIMARÃES, M.; MIRANDA, E. E. DE. Um método para a determinação automática de áreas de preservação permanente em topos de morros para o Estado de São Paulo. In: SIMPÓSIO BRASILEIRO DE SENSORIAMENTO REMOTO, 12., 2005, Goiânia. Anais... São José dos Campos: INPE, 2005. p. 30613068 .

INSTITUTO AGRONÔMICO DO PARANÁ-IAPAR. Uso e manejo dos solos de baixa aptidão agrícola. Londrina, 1999. 270 p. (IAPAR. Circular técnica)

INSTITUTO NACIONAL DE PESQUISAS ESPACIAIS - INPE. Manual do Spring. São José dos Campos, 2005. SPRING: Tutorial de Geoprocessamento. São José dos Campos, 1999. Versão Windows

LOCH, R. E. N.; KIRCHINER, F. F. Classificação de imagens multiespectrais Landsat TM e feições de textura: mapeamento da cobertura vegetal. Revista Floresta, Curitiba, v. 27, n. 1/2, p. 41-58, 2000.

MAGAlhâES, C. S.; FERREIRA, M. A. Áreas de preservação permanente em uma microbacia. Informe Agropecuário, Belo Horizonte, v. 1, n. 207, p. 33-39, nov./dez. 2000.

NASCIMENTO, M. C.; SOARES, V. P.; RIBEIRO, C. A. A. S.; SILVA, E. Uso do geoprocessamento na identificação de conflito de uso da terra em áreas de preservação permanente na bacia hidrográfica do Rio Alegre, Espírito Santo. Ciência Florestal, Santa Maria, v. 15 , n. 2, p. 207-220, 2005. 
OLIVEIRA, M. J. Proposta metodológica para delimitação automática de áreas de preservação permanente em topos de morro e em linha de cumeada. 2002. 53 f. Dissertação. (Mestrado em Ciência Florestal) - Universidade Federal de Viçosa, Viçosa, 2002.

PESSOA, M. C. P. Y.; LUCHIARI, A. J.; FERNANDES, E. N.; LIMA, M. A. Principais modelos matemáticos e simuladores utilizados para análise de impactos ambientais das atividades agrícolas. Jaguariúna: EMBRAPA/CNPMA, 1997. 83p. (EMBRAPA/CNPMA. Documentos, 8).

PRIMACK, R. B.; RODRIGUES, E. Biologia da conservação. Londrina: Ed. Rodrigues, 2001. 328p.

RAMALHO FILHO, A.; BEEK, K. J. (Ed.). Sistema de avaliação da aptidão agrícola das terras. 3. ed. Rio de Janeiro: EMBRAPA/CNPS, 1995. 65 p..

REIS, T. E. S. Determinação da compatibilidade de uso do solo e proposta de restabelecimento de áreas de reservas florestais em Bandeirantes - PR, através de análise de imagens e geoestatística. 2003. 145 f. Tese (Doutorado em Agronomia) - Universidade Estadual de Londrina, Londrina, 2003.

REIS, T. E. S.; BARROS, O. N. F.; REIS, L. C. Uso de sig e geoestatística no estudo da dependência espacial e estabelecimento de superfície de correlação de fragmentos florestais em áreas de baixa aptidão agrícola. In: MOSTRA DO TALENTO CIENTÍFICO, 4., 2004, São Paulo. Anais... São Paulo: GIS BRASIL, 2004. CD ROM..
RIBEIRO, C. A. A. S.; SOARES, V. P.; OLIVEIRA, A. M. S.; GLERIANI, J. M. O desafio da delimitação de áreas de preservação permanente. Revista Árvore, Viçosa, v. 29, n. 2, p. 203-212, 2005.

SANO, E. E.; ASSAD, E. D.; ORIOLI, A. L. Monitoramento da ocupação agrícola. In: ASSAD, E. D.; SANO, E. E. (Ed.). Sistema de informações: aplicações na agricultura. Planaltina: EMBRAPA/CPAC,1998. p. 179-190.

SHIMABUKURO, E. Y.; BATISTA, E. T.; MELLO, M. K.; MOREIRA, J. C.; DUARTE, Y. Using shade fraction image segmentation to evaluate deforestation in Landsat Thematic Mapper images of Amazonian region. Internacional Journal Remote Sensing, London, v. 19, n. 3, p. 535-541, 1998.

TOWSHEND, J. R. G. Environmental database and GIS. In: MAGUIRE, D. J., GOODCHILD, M. F.; RHIND, D.W. Geographical information systems: principles and applications. New York : Longman Scientific \& Technical, 1992. p. 201-205.

VALERI, S. V.; SENÔ, K. C. A. Situação das propriedades agrícolas na região de Jaboticabal, Estado de São Paulo. In: VALERI, S. V. et. al..(Ed.). Manejo e recuperação florestal: legislação, uso da água e sistemas agroflorestais. Jaboticabal: FUNEP, 2003. p. 130-141.

XAVIER DA SILVA, J. Geoprocessamento e análise ambiental. Revista Brasileira de Geografia, Rio de Janeiro, v. 54, n. 3, 1992, p. 47-61. 